\section{Hemorragia digestiva alta en paciente con púrpura} difusa antral

\section{Sr. Director:}

La Púrpura de Schölein-Henoch (PSH) es una vasculitis por hipersensibilidad que consiste en una inflamación de las arteriolas, capilares y vénulas postcapilares. La causa puede ser desconocida o secundaria a otros procesos como infecciones por virus, bacterias o fármacos (1). Esta vasculitis es propia de la infancia, aunque se puede diagnosticar ocasionalmente en pacientes adultos, como es el caso que presentamos.

Varón de 41 años que consultó en urgencias por dolor abdominal y vómitos hemáticos. Como antecedentes destacaba una hipertensión arterial y diabetes en tratamiento. Diagnosticado de púrpura de Schölein-Henoch seis años antes, tras un ingreso por púrpura palpable en miembros inferiores y dolor abdominal, recibió tratamiento con esteroides durante dos meses con mejoría de la sintomatología. En el actual ingreso, el paciente presentaba dolor abdominal espontáneo y a la palpación, sobre todo en hemiabdomen superior, destacando la presencia de una púrpura difusa en piernas y muslos. Se colocó una sonda nasogástrica apreciando la salida de contenido biliar mezclado con sangre digerida. La coagulación era normal, hemoglobina de $16,2 \mathrm{gr} / \mathrm{dl}$ y un hematocrito del $46 \%$, plaquetas normales y leucocitosis de 15.720 con 10.170 neutrófilos. Presentaba una glucemia elevada de $159 \mathrm{mg} / \mathrm{dl}$, una urea alta de $87 \mathrm{mg} / \mathrm{dl}$ y una creatinina normal de $1,1 \mathrm{mg} / \mathrm{dl}$. Los iones, enzimas cardiacas y la amilasa en sangre y orina eran normales. La tensión era de 135/70 $\mathrm{mmHg}$, con una frecuencia cardiaca de $90 \mathrm{lpm}$. El estudio electrocardiográfico, la radiografía de tórax y abdomen no presentaron alteraciones significativas. Decidimos realizar una endoscopia digestiva alta urgente, encontrando un estómago con contenido biliar y sangre digerida, una mucosa gástrica eritematosa de forma parcheada en fundus y cuerpo gástrico y lesiones purpúricas difusas en todo el antro gástrico (Fig. 1), donde destacaba la existencia de áreas de mucosa atrófica y de color violáceo sobre todo en su cara anterior. A nivel duodenal, se observaron algunas lesiones petequiales puntiformes. No se realizó ninguna terapéutica endoscópica al tratarse de una lesión difusa y no presentar sangrado activo. El paciente recibió tratamiento con omeprazol intravenoso y terapia inmunosupresora con buena respuesta.

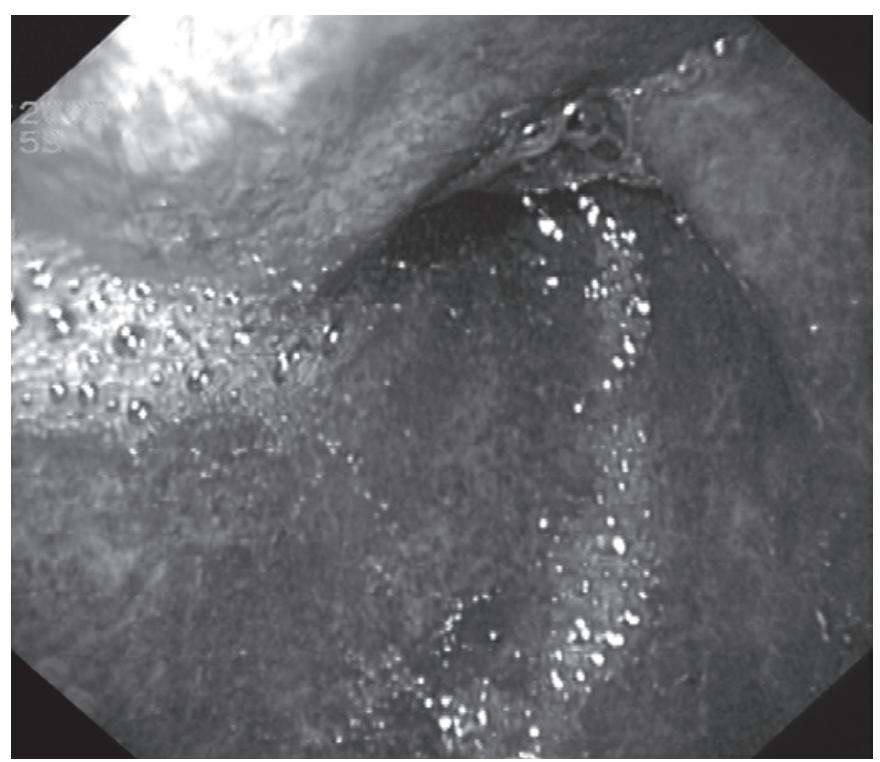

Fig. 1. Antro gástrico con púrpura en la mucosa.
La PSH se manifiesta como una púrpura que predomina en zonas declives y sometidas a presión de distribución simétrica. Las lesiones duran entre una y cuatro semanas, a veces se acompaña de febrícula y postración. Además de las manifestaciones cutáneas, es frecuente la afectación renal en forma de glomerulonefris con hematuria, proteinuria y artritis, que son leves y transitorias (1)

La PSH puede también cursar con manifestaciones abdominales, hecho que se considera un criterio diagnóstico. El síntoma principal suele ser el dolor abdominal cólico debido a la obstrucción intestinal por edema submucoso, que puede acompañarse de vómitos, nauseas, diarrea, hemorragia con sangrado oculto, melenas y/o hematemesis $(2,3)$.

La localización digestiva más frecuente de las lesiones es en duodeno y yeyuno. En la endoscopia pueden visualizarse erosiones o ulceraciones gástricas o duodenales, con lesiones purpúricas y áreas submucosas hemorrágicas (4).

Para su diagnóstico es necesario realizar una biopsia de la lesión cutánea. Aunque es una patología que desaparece y puede volver a recidivar, suele presentar un curso benigno, no obstante también se pueden encontrar formas graves e incapacitantes. Con respecto al tratamiento, es una enfermedad que suele desaparecer sin ningún tratamiento específico, aunque si debe buscarse el agente causal. Además habrá que tratar los síntomas asociados y aplicar un determinado tratamiento dependiendo del órgano afectado, habitualmente con corticoides y/o inmunosupresores (1).

R. Baños Madrid, F. Alemán Lorca ${ }^{1}$, M. Alajarín Cervera, A. Serrano Jiménez, F. Alberca de las Parras, J. Molina Martínez, F. Carballo Álvarez

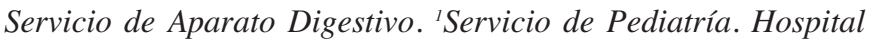
Universitario Virgen de la Arrixaca. Murcia

1. Alarcón-Segovia D, Gil Aguado A, Xutglá MC. Vasculitis. En: Farreras P, Rozman C, editores. Medicina Interna. 14. ed. Madrid: Harcout, 2000. p. 1278-95

2. Esaki M, Matsumoto T, Nakamura S, Kawasaki M, Iwai K, Hirakawa $\mathrm{K}$, et al. GI involvement in Schönlein-Henoch purpura. Gastrointest Endosc 2002; 56: 920-3.

3. Espinet E, Muñoz-Navas M, Súbtil JC, de la Riva S, Betés M, Fernández-Urién I, et al. Utilidad de la endoscopia en la hemorragia digestiva por vasculitis. Gastroenterol Hepatol 2004; 27: 403-7

4. Novak J, Marki-Zay J, Csiki Z, Sebesi J, Takats A, Sipka S. SchönleinHenoch purpura in adulthood (gastrointestinal manifestation and endoscopy). Z Gastroenterol 2001; 39: 775-82.

Debilidad muscular como primera manifestación de un panhipopituitarismo secundario a un síndrome de silla turca vacía

\section{Sr. Director:}

El síndrome de la silla turca vacía (STV) se relaciona con distintos disturbios endocrinos y/o neurológicos provocados por la herniación del espacio subaracnoideo en el interior de la misma (1) y aunque su etiología es incierta se sabe que la presión intracraneal constituye uno de sus principales factores patogenéticos (2). Es una entidad relativamente frecuente en la población general (5-23\%), 
que suele asociarse generalmente a insuficiencia hipofisaria parcial y en menos ocasiones a panhipopituitarismo (3-10\%) (3).

Presentamos un caso de panhipopituitarismo en relación con un síndrome de STV en el que la debilidad muscular es su primera y única manifestación clínica, lo que nos hizo barajar distintas hipótesis diagnosticas. Se trata de una mujer de 76 años sin antecedentes valorables y con una vida muy activa para su edad, que ingresa por presentar como única sintomatología un cuadro de debilidad muscular más acentuado en los dos últimos meses, que se incrementa a lo largo del día y disminuye tras el reposo. En la exploración destaca la disminución de la fuerza muscular sobre todo en los grupos musculares proximales, el tono muscular estaba conservado y no se apreciaban atrofia ni fasciculaciones significativas. La analítica, estudios radiológicos toraco-abdominales, sonografía abdominopélvica y panendoscopia digestiva estaban dentro de la normalidad. Por todo ello se incide en el estudio de la debilidad muscular, encuadrándola en el patrón miopático y por alteración en la unión neuromuscular dado su carácter intermitente, pero la normalidad de los enzimas musculares, la negatividad de los AchR y la ausencia de alteraciones en el estudio EMG descartaban la patología a ese nivel. Se sugiere entonces la posibilidad de una alteración psíquica como causa provocadora y el examen psiquiátrico concluye con el diagnóstico de "síndrome depresivo en una paciente con personalidad de tipo ciclotímico". La falta de respuesta al tratamiento instaurado y la misma asociación del síndrome depresivo con la debilidad muscular nos hizo descartar una causa tiroidea. La sonografía tiroidea era normal al igual que la determinación repetida de TSH

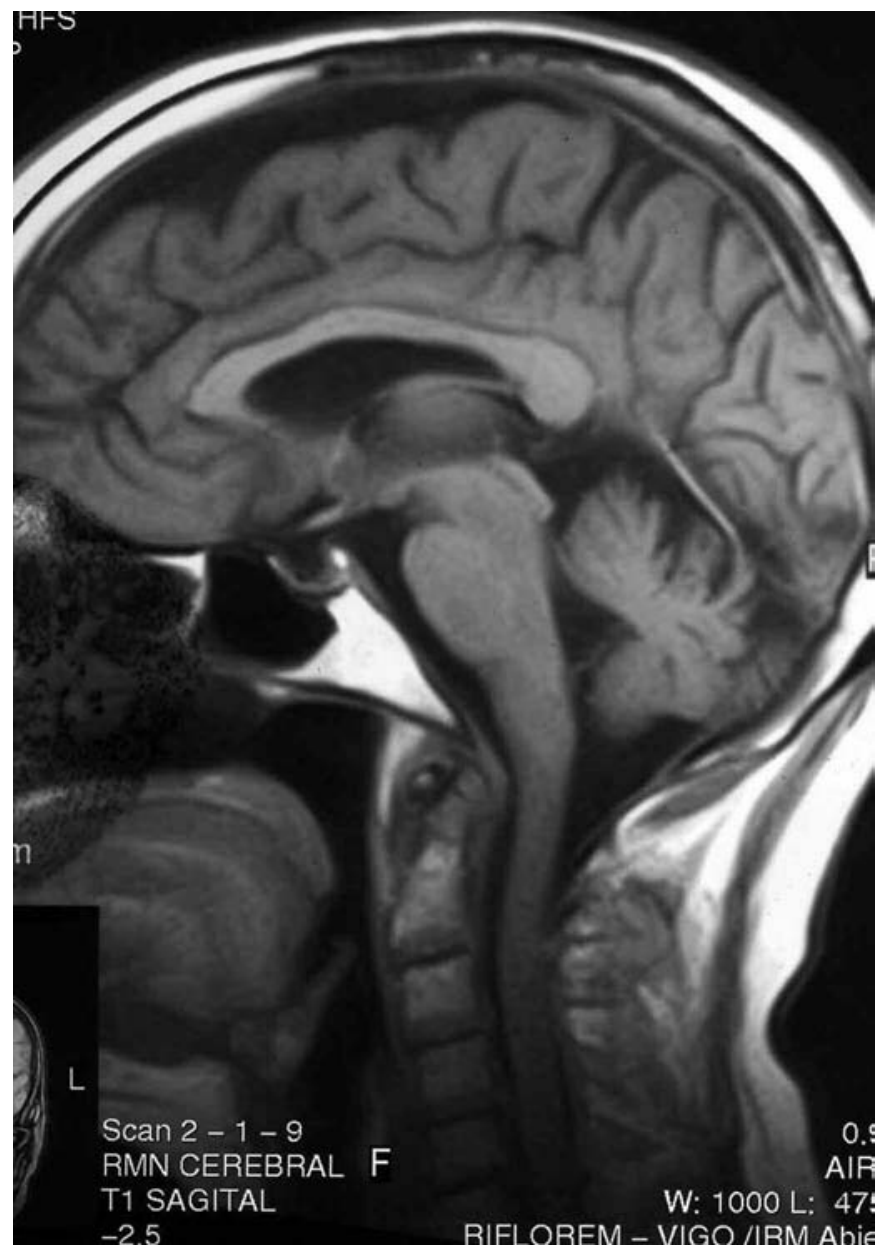

Fig. 1. y T3, al tiempo que la T4 presentaba niveles bajos: $<0,40 \mathrm{ng} / \mathrm{ml}$ $(0,7-1,48)$. Ante la posible existencia de un hipotiroidismo secundario se estudian otros ejes hipotálamo-hipofisarios con los resultados siguientes: IGF-I (somatomedina C): $17 \mathrm{ng} / \mathrm{ml}$ (49-250), LH: 0,1 mUI/ml (11,3-39,8), FSH: $1 \mathrm{mUI} / \mathrm{ml}(21,7-153)$, Cortisol $8 \mathrm{~h}(\mathrm{am}): 1,9 \mathrm{microg} / \mathrm{ml}$ (5-25) y Prolactina: $12,5 \mathrm{microUI} / \mathrm{ml}$ (320). La RNM determinó que la causa provocadora de su panhipopituitarismo se debía a un síndrome de STV (Fig.1) al mostrar una silla turca ocupada en su mayor parte por el LCR, sin descenso del quiasma óptico, y con vestigios de la glándula pituitaria en la región del suelo. Se le administra inicialmente Hidrocortisona (30 mg/día) y Levotiroxina (50 mcg/día), con lo que la paciente recupera su estado basal y permanece asintomática y con normalización analítica en los controles posteriores al alta hospitalaria.

El término de silla turca vacía, establecido por Busch en 1951 después del estudio necrópsico de 700 hipófisis (4) e introducido en la clínica en 1973 tras la descripción de Neelon (5), constituye un cuadro anátomo-radiológico específico secundario a la invaginación aracnoidea en la silla turca, que aparece total o parcialmente rellena de LCR. En realidad no es que la silla turca esté totalmente vacía, si no que la hipófisis está rechazada hacia el fondo de la misma, a veces a modo de lámina que almohadilla su suelo dando esa sensación, de ahí que algunos autores prefieran llamarlo síndrome de la hipófisis laminar. Aunque su etiología es incierta se han propuesto como posibles causas la existencia de defectos congénitos, necrosis de quiste o tumor hipofisarios, enfermedad autoinmune (6), involución tras hipertrofia o el incremento de la presión intracraneal. Representa un cuadro clínico heterogéneo caracterizado por signos de hipertensión intracraneal y de disfunción hipofisaria, dependiendo del grado de afectación glandular (7). Así, la afectación en más del 70\% de la adenohipófisis provocará un cierto grado de disfunción hipotálamo-hipofisaria mientras que si supera el $90 \%$ se presentará un panhipopituitarismo (8), situación que no sobrepasa el 10\% en las series más numerosas (9). Es de destacar que la prolactina puede estar elevada o normal, como en nuestro caso, ya que es la única hormona hipofisaria que se halla sometida a un control negativo por el hipotálamo que se pierde por la compresión infundibular, lo que hace que sea la hiperprolactinemia la alteración hipofisaria más frecuentemente detectada (25-30\%) (10). Su diagnóstico es fundamentalmente de imagen, en el que la RNM es la técnica de mayor rentabilidad diagnóstica al mostrar la silla turca total o parcialmente rellena de LCR (9) y su tratamiento se basa en la sustitución hormonal deficitaria (8), tras el cual suele seguir una evolución favorable.

\section{Paz Flores, J. Rosales Carballa, J. Blanco Loberías ${ }^{1}$}

Servicio de Medicina Interna B. ${ }^{1}$ Servicio de Psiquiatría. Complejo Hospitalario de Pontevedra (CHOP). Pontevedra

1. De Marinis L, Bonadonna S, Bianchi A, Maira G, Giustina A. Primary empty sella. J Clin Endocrinol Metab 2005; 90: 5471-7.

2. Maira G, Anile C, Mangiola A. Primary empty sella syndrome in a series of 142 patients. J Neurosurg 2005; 103: 831-6.

3. Blake Tyrrell J, Findling JW, Aron DC. Hypothalamus and pituitary. En: Greenspan FS, Baxter JD (ed). Basic and Clinical Endocrinology. Lange 1994: 64-127.

4. Busch W. Die Morphologie der sella turcica und beziehungen zur hypophyse. Virchows Arch 1951; 320: 437-58.

5. Neelon FA, Goree JA, Lebovitz HE. The primary empty sella: clinical and radiographic characteristics and endocrine function. Medicine 1973; 52: 73-94.

6. Komatsu M, Kondo T, Yamauchi K et al. Antipituitary antibodies in patients with the primary empty sella síndrome. J Clin Endocrinol Metab. 1988; 67: 633-8. 
7. Durodoye OM, Mendlovic DB, Brenner RS, Morrow JS. Endocrine disturbances in empty sella syndrome: case reports and review of literature. Endocr Pract. 2005; 11: 120-4.

8. Rennenberg RJ, Bravenboer B, Wolffenbuttel BH. Empty sella syndrome as the cause of panhypopituitarism. Ned Tijdschr Geneeskd 2004; 148: $33-6$

9. Sartre J, Herranz de la Morena A, López Guzmán A, Gómez Pan A, Pallardo Sánchez LF. Silla turca vacía primaria: evaluación clínica, radiológica y hormonal. Rev Clin Esp 1992; 191: 481-4.

10. Donadio F, Barbieri A, Angioni R, Mantovani G, Beck-Peecoz P, Spada A, Lania AG. Patients with macroprolactinaemia: clinical and radiological features. Eur J Clin Invest. 2007; 37: 552-7.

\section{Leiomiosarcoma primario pulmonar de progresión lenta}

\section{Sr. Director:}

El leiomiosarcoma es un tumor infrecuente que procede de células musculares lisas, afecta en muy raras ocasiones al pulmón de forma primaria, siendo más frecuente la localización en el tracto gastrointestinal o genital femenino; las lesiones pulmonares suelen ser metástasis de dichas localizaciones. El diagnóstico se apoya fundamentalmente en la clínica, siendo necesario la realización de pruebas de imagen y estudio anatomopatológico para confirmarlo. Su presentación como una masa pulmonar en los estudios de imagen, a menudo supone un reto diagnóstico. A continuación presentamos el caso de una paciente diagnosticada de leiomiosarcoma primario pulmonar a partir del hallazgo casual como masas de localización intraparenquimatosa, en la radiografía simple de tórax.

Mujer de 68 años de edad, que acudió al servicio de Urgencias de nuestro hospital por haber presentado un esputo hemoptoico autolimitado.

Tenía antecedentes personales de crisis renoureterales de repetición y diabetes mellitus tipo 2. Ocho años antes fue estudiada por lesiones pulmonares. La paciente refería contacto con perros en la infancia y como antecedentes familiares, madre intervenida en dos ocasiones de quistes hidatídicos.

A su llegada al hospital se encontraba asintomática y refería un episodio de hemoptisis de escasa cuantía, que no se acompañó de dolor torácico, disnea, ni fiebre. Describía así mismo, un único episodio de similares características en los meses previos al que no dio importancia.

La paciente se encontraba eupneica, con saturaciones de oxigeno basales del $98 \%$, afebril, con buena coloración de piel y mucosas, y sin hallazgos patológicos en la auscultación pulmonar. No hubo otras alteraciones de interés en la exploración física.

En el servicio de Urgencias se realizó una analítica básica con hemograma, bioquímica y coagulación que fueron normales. La radiografía postero-anterior de tórax mostraba una imagen de aumento de densidad en región basal derecha, de bordes nítidos, en contacto con la pared torácica, y otra imagen de similares características en pulmón izquierdo (Fig. 1). Ante estos hallazgos se decidió el ingreso de la paciente en el Servicio de Medicina Interna para completar estudio, realizándose durante el mismo una TC torácica (Fig. 2).

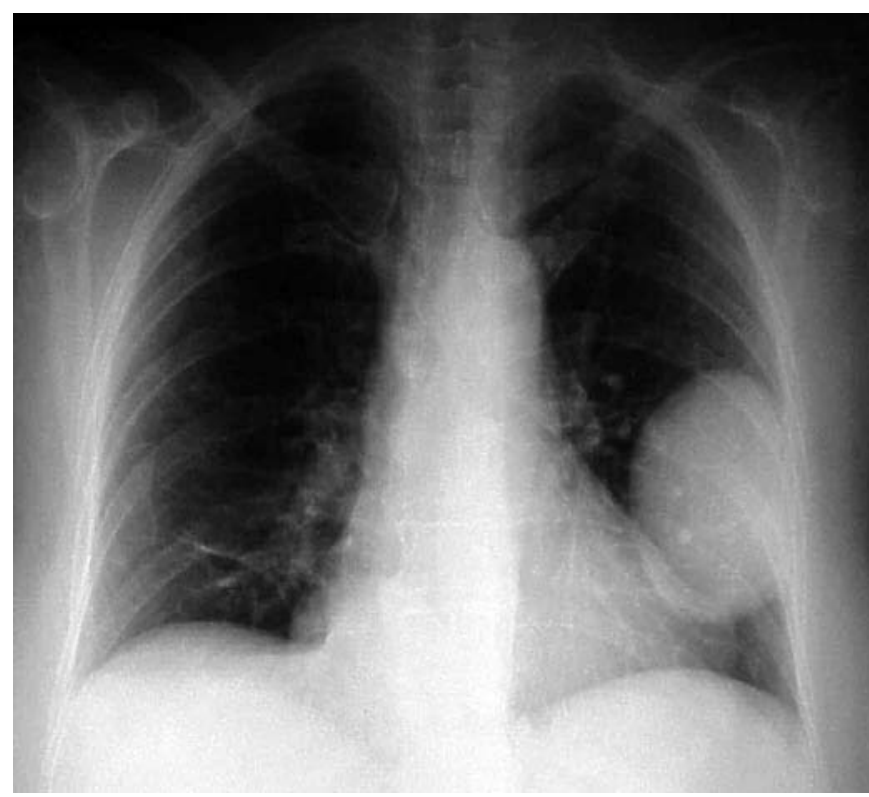

Fig. 1.

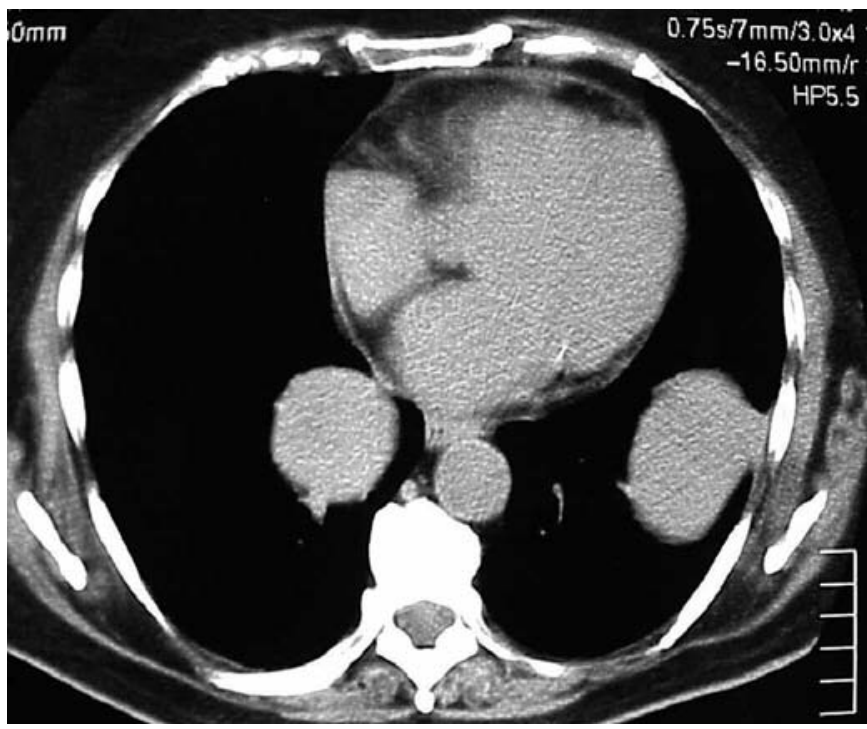

Fig. 2.

En la TC tóraco-abdominal, realizada durante su ingreso, se visualizó una tumoración basal derecha que ocupaba el receso pleuro-acigo-esofágico $(5,5 \mathrm{~cm})$ y otra tumoración de similares características en hemitórax izquierdo $(7 \mathrm{~cm})$. Ambas lesiones en extenso contacto con la superficie pleural (Fig. 2). A nivel abdominal no se encontraron alteraciones. Se realizó PAAF guiada por TC de una de las masas, la cual fue informada como tumor mesenquimal benigno de células fusiformes. El resto de las pruebas diagnósticas realizadas (analítica completa con marcadores tumorales y serología de hidatidosis), resultaron normales.

Al revisar la historia clínica de la paciente, se constató que fue estudiada 8 años atrás por lesiones pulmonares, realizándose una TC tóraco-abdominal donde se objetivaron masas pulmonares similares, aunque de menor tamaño a las referidas en la TC actual. En aquél momento se realizó PAAF que fue sugerente de 